\title{
Metaphyseal chondrodysplasia, Spahr type
}

INSERM

\section{Source}

INSERM. (1999). Orphanet: an online rare disease and orphan drug data base.

Metaphyseal chondrodysplasia, Spahr type. ORPHA:2501

A rare, genetic, primary bone dysplasia disease characterized by usually moderate, postnatal short stature, prog ressive genu vara deformity, a waddling gait, and radiological signs of metaphyseal dysplasia (i.e. irregular, sclerotic and widened metaphyses), in the absence of biochemical abnormalities suggestive of rickets disease. Intermittent knee pain, lordosis, and delayed motor development may also occasionally be associated. 